\title{
Translating Poetry: Interface with Emily Dickinson's Poems
}

Madhavi Apte*

Translating poetry, successfully, is considered difficult, or even impossible (George Steiner), universally. There have been innumerable theories coming up every now and then. Translators have taken up this task for about 2000 years, each age with its own theories, and yet, there is no clear-cut 'prescription' as to how to translate poetry. Researchers and scholars, of late, however, do not think in terms of "prescriptive/normative" theories, but in terms of descriptive/empirical methods, and eclectic approach to translation. Views on the translation of poetry have ranged from translating poems into prosaic paraphrases (Vladimir Nabokov) to "verse to verse' poetic translations. Absolute fidelity to the source text, in every aspect, is the other extreme and any translation less than that is considered a compromise.

"Poetry translation has been called the art of compromise and its success will always be a question of degree."

However, translation as transfer from language to language, text to text, and culture to culture, and even from "existential state to state" as Boylan puts it, will continue to engage people and give them the pleasure of experiencing a new creation. They will also offer readers and critics of translation food for thought. The activity of translation occurs through an interface, the translator, whose interpretation also matters a lot, in poetic translations. All the translations do not get compared with the source texts, not at least microscopically, as it usually happens with poetry, because the poems are small in size, and compact in expression. Nobody tries to compare the translation of a novel line by line. This is only the business of scholars of translation studies, as the target language readers would just continue to enjoy translated poetry as if it was a new poetic experience in their own language.

Madhavi Apte teaches Linguistics and Applied Linguistics to postgraduate students at Dr. Babasaheb Ambedkar Marathwada University, Aurangabad, India.

Translation Today Volume (1), No (1) Mar. 2004 (C CIIL 2004. 
As first translation theory to prescribe rules, or guide a translator, I would be inclined to subscribe to the view expressed by about theorization as an integral part of translational competence. "Although every translator needs to know, a good deal about grammar, rhetoric, terminology, world knowledge, common sense, and strategies for getting paid correctly, the specifically translational part of their practice is strictly neither linguistic, commonsense, nor commercial. It is a process of generating and selecting alternative texts."

This definition recognizes that there is a mode of implicit theorization within translational practice, since the generation of the alternative translation theories depends on a series of at least intuitively applied hypotheses. The theorization may or may not become explicit but the ability to develop and manipulate hypothetical translation theories is an essential part of translational competence. Robert de Beaugrande (in press), calls this competence, 'translatability': "both theory and practice of translation might profit by centering upon the conception of translatability, defined as the dialectical interaction between what would be required of translators and what actually gets achieved... a bi-directional vision of translator ability: the ways in which competent translators can perform and do perform, as well as how their performance can affect and develop their competencies". This same bi-directional vision and activity of the translator can be seen as the "interface".

The concept of translatability implies that every translator does know and have his/her own theory of translation, and keeps revising it as and when he/she realizes that there is a need for a revision. Beaugrande mentions it in his Factors in a Theory of Poetic Translating (1978), and promotes practice driven theories rather than abstract prescriptive theories. Most conscious translators try to achieve as much as possible and try to go as close to the original as they can. The translator's effort seeks to maintain the secret essence of the source language and the poem, as well as its structural aspects. Whereas some theorists like Beaugrande assign translatability to the translator ability, others like the Italian poet and translator Italo Calvino trusts that every language has its 'secret essence', and his concept of its translatability is that of its 
international communicability, which is quite different from Beaugrande's.

Calvino's American translator, William Weaver believes that a translation should not be approached as a scientific task, but as a creative endeavour. According to Weaver, knowing the author better would help a translator in translating their works more than a theory of translation could. My experience with translating Emily's poems agrees with Weaver's. Before starting the actual translation activity, I read through at least half a dozen biographies of Emily Dickinson.

In my own translations, I have tried to achieve the best possible effects and retain the essence of each poem in question while translating it into the target language Marathi, making the poems more audience based with regard to cultural aspects. The paper, from here on, presents three aspects of my own translation experience with reference to Emily Dickinson's poems namely, linguistic, cultural and managerial.

Translating Emily Dickinson has been an uphill task, not for me alone, but for poets and translators like Paul Celan, (A Jewish survivor of the Holocaust), who is himself a notoriously difficult poet to translate. Walker writes: "---could we have the peculiar grammar of Emily Dickinson beside the lyricism of Baudelaire if both poets were constrained to the same language? However, such richness provides difficulty for those who are called upon to translate poetry from one language to another---". However, I am not aware of many other translators trying their hand at Emily's. poems.

Emily Dickinson is with no room for argument, one of the greatest and most unusual poets in the history of American literature. At the same time, she is a very difficult poet to understand and interpret, due to the strange punctuation practice, which makes her syntax incomprehensible in many places. Especially, for the purpose of translation, into a language such as Marathi, which is typologically, as well as culturally so different, Emily's poems pose formidable challenges. 


\section{Linguistic Interface with Emily's poems:}

Linguistic equivalence is the most significant aspect of a translation, and especially, a poetic translation. The linguistic typology of English and Marathi is different in that, Marathi is a verb-ending language and English has the verb in the middle. This changes the positions of various parts of speech and grammatical elements such as the position of the subordinate clauses, the prepositions, and other syntactic elements as well. Each language on the other hand, is loaded heavily with cultural connotations, especially in words and phrases, and one would consider connotative translation as closer to the source than denotative translation. Denotative or literal translation results in disaster, or, at times, it is even impossible as cited in the example below. Therefore, words need to be chosen most carefully, or even they need to be created with appropriate meanings in the context. Just as a dictionary, a thesaurus, or an encyclopaedia would offer a lot of help; no doubt, the translator's interpretation plays a big role in the process of selecting certain words. The syntax plays an equally important role in the interpretation of some expressions. The target language demands syntax, which must suit the idea expressed in the source language text. Even a small problem like the gender of a noun presents a challenge, and the whole sentence/poem, and the notion in the original text needs to be considered afresh.

The example, I would like to cite here, is of the poem, 'The Soul selects her own Society'.

Emily makes use of capital letters for certain special nouns. Marathi has no such system of capital letters. So, what she intended to convey through the capital letters could not be brought out in the Marathi text. Moreover, the gender of 'soul' in Marathi is masculine. In this poem the soul is personified as a woman. The whole treatment of the concept of the soul as a woman would have been impossible for the lack of lexical equivalence in the target language, and the related syntax thereof. Creativity had to be resorted to in this translation. After due thinking, I came to a solution. I coined a new word, the feminine of aatmaa as aatminee in Marathi and took my translation as close to the original idea as possible. There were other occasions when such decisions resorting 
to creativity were necessary. Another example of such a decision was regarding the title of my published book itself. I was particular that I gave an apt title Malena, to my book. After spending a good amount of time and mental energy on what would be the most appropriate description of Emily's poems, and what title would be the most befitting for my book of translations, one day it came to me in a most creative moment, like a flash. I called it Goodharammyaa Emily. Goodha (mysterious) and Rammya (entertaining/interesting) are two different adjectives. In Marathi, they do have some association in the context of something mysterious as well as interesting, usually associated with detective stories, or novels. But they are generally used as two separate words and not as a compound word. To describe Emily's poetry, making them into a compound word and in a totally different context, was a creative decision again. Not only does the description goodharammyaa mean that she is herself mysterious as well as interesting, but the compound also means that she was interested in the mysteries of the world in an interesting manner.

Regarding syntax in translation, Houbert writes: "The translation process becomes two fold: firstly, the translator needs to detect potential discrepancies and flaws in the original text and understand the meaning they intend to convey...secondly...the translator will undo the syntactic structure of the original text and then formulate the corresponding message in the target language, thus giving the original text added value in terms of both wording and impact".

In the case of Emily's poems, the syntax of the translated poems had to be different due to the typological differences between the source and the target languages. And yet, besides that, keeping the lines in the same length and content did not require any extraordinary effort. The cross-linguistic communicability, or the translatability of her poems made it possible with a kind of ease at times. The following examples demonstrate the fact that her lines were accessible to translation most of the times. This was possible due to the characteristic shorter lines packed with meaning. 


\section{Original: no. 1478}

Look back on time, with kindly eyes-

He doubtless did his best-

How softly sinks that trembling sun

In Human Nature's West-

\section{Translation: Marathi}

gatakaalaakaDe pahaawa sahrudaytene-

tyaacha sarwaswa laawlay tyaane paNaalaa-

ksaa haluuch buDtoy to tharthartaa suurya

manushya swabhaawaachyaa paschimela

(capital letters for retroflex sounds)

\section{Word-to-word Glossing:}

gonebacktime at be looked kindheartedly-

his all put he stake at-

how softly sinks that trembling sun

human nature of west to

It was possible not only to bring out the essence of the poem in the exact number of lines, but also with good rhyming.

\section{Original: no. 1472}

To see the summer sky

Is poetry, though never in a book it lie-

True poems flee-

\section{Translation: Marathi}

unhaaLi aakash nyaahaaLna

kaawya aahe, koNtyaahi pustakaat naslela-

kharyaa kavitaa chakwun jaatat-

\section{Word-to-word Glossing:}

The summer sky to see

Poetry is, any book in not has been-

True poems flee- 
There were also those poems, which exhausted me completely, and yet, I am not really satisfied with the translation, though the essence is not lost, hopefully.

\section{Original: no. 323}

As if I asked a common alms,

And in my wondering hand

A Stranger pressed a Kingdom, And I, bewildered, stand -

As if I asked the Orient

Had it for me a morn-

And it should lift its purple Dykes,

And shatter me with Dawn!

\section{Translation: Marathi}

janu kaahi mi saadhaaran bhikshaa maagiti, aani maajhyaa utsuk haataat

saamraajya kombla kunaa anolkhyaana, aani mi, bhaambhaawleli, ubhi-

janu kaahi maagitlaà hota mi puurwaprakhanDa, hoti tyaachyaajawal maajhyaasaaThi sakaalaani uchlun ghetiyaa astyaa tyaane aap;yaa jaambhalyaa kumpanbhinti, karun shatakhanDit malaa pahaaT tejaane!

(capital letters for retroflex sounds)

\section{Word-to-word Glossing:}

As if I common alms asked, And my wondering hands in Kingdom pressed some stranger, And I, bewildered, standAs if asked had I the Orient, Was him with me for a mornAnd lifted had he His purple dykes, Making hundred pieced me with dawn glory!!

The typological differences between English and Marathi necessitate some syntactic changes: the prepositions become 
postpositions, auxiliary verbs come after the main verb, and the verbs appear at the end of the sentences/lines are much shorter and simpler. Franklin has discussed Paul Celan's translation of Emily's poem, 'Because I could not stop for Death' in a great detail where she has compared his German syntax with the original English, and many other changes he had to make deviating from the original. She has expected $100 \%$ fidelity from him and has criticised Celan for not having been able to attain it. I think that such criticism is unfair because one must understand that no two languages in this world are identical. A translation should be able to do justice to the original and should not create something totally different. But a translator has to be granted the flexibility that a target language requires him/her to express and bring out the essence of the original. Expecting 100\% fidelity is ignoring the fact that the text is being transferred. It is like expecting an Eskimo to live in an igloo even when he travels to India. Asking for $100 \%$ fidelity is being completely unreasonable.

The transfer of phonetic elements from the source into the target language is another myth. Joanna Janecka writes:

"The effect poetry evokes is based on its inner musical value, and thus the translation, to be successful, must function as a poem in the similar way it does in the source language."

It is difficult to agree with her views entirely, reading the sound effects within a translated poem, though it is true that the translated text must also exist as a poem in the target language. Languages . select their own set of sounds. Their words do not always resemble in the sound quality, unless they are onomatopoetic. One can understand the expectation that if there are any lines rhyming in the source text, there should be good rhyming lines in the target language text too. Or, if there is alliteration in the source text, then that effect should be achieved in the target language as well. However, it is too much to expect that the same associations through sounds can be evoked in the translated text as in the original. To quote Janecka, "when translating poetry, one has to preserve the artistic associations evoked by the poem as close to the original as possible. 
When most of the associations are lost (and the sound associations are the most important of all) the translation turns out to be unsuccessful and fails to the author's intent." To assume that the same sound associations would not mean the same thing to the target language reader. Therefore, only relevant associations in the target language text need to be resorted to, to match the originals, which would please the target language reader. Octavio Paz appears to be more realistic in this context. "The ideal of poetic translation...consists of producing analogous effects with different implements."

In my experience, while translating the poems, rhyming and alliteration happened without much effort. This has created a harmonious effect and many poems sound as if they were written in Marathi as originals. They have also retained the essence and the content of the poems quite well. A couple of examples are as follows:

\section{Original no. 111}

The Bee is not afraid of me,

I know the butterfly.

The pretty people in the woods

Receive me cordially.

The Brooks laugh louder when I come-

The Breezes madder play;

Wherefore mine eye silver mists,

Wherefore, Oh Summer's Day?

\section{Translation: Marathi}

Malaa bheet naahi madhmaashi.

OLakh maajhi phulpaakhraashi. Raanaatli hi dekhni manDaLi

Swaagat kartaat maaza khaashi-

Maajhyaa yeNyaane o Dhe khidaltaat-

Waare dekhil dhumaakuL ghaaltaat, Kashaalaa maajhyaa DoLyaat chanderi dhuka, 
Kashaalaa re, unhaaLyaachyaa diwsaa?

[Capitals for retroflex sounds]

\section{Word-to-word Glossing:}

Me to fears not the bee.

Acquaintance my butterfly with.

Woods from these pretty people

Welcome do me specially-

My coming makes brooks laugh louder-

Breezes madder play;

Wherefore my eye in silver mist,

Wherefore Oh, summer's day?

\section{Original: no. 124}

In lands I never saw- they say

- Immortal Alps look down-

Whose bonnets touch the firmament-

Whose sandals touch the town-

Meek at whose everlasting feet

A myriad Daisy play-

Which Sir, are you and which am I

Upon an August day?

\section{Translation: Marathi}

asa mhaNtaat- mi kadhi na paahilelyaa dedhaat amar Alps ubhe dimaakhaattyaanche shiraapech gaganaalaa bhiDtaat tyaanche joDe nagaraalaa sparshataat. Wlneet tyaanchyaa chirantan charaNaashl Lakshaawadhi phule astaat ramleliTyaatle kuThale, mahaashay tumhi an kuThale mi Ekhadyaa unhaaLi diwashi? 
Translating cultural elements in a translated text is much more difficult. As stated by Alvarez-Vidal, approaching a culture implies beginning a process of translation. "Translation is not the production of a text equivalent to another text, but rather a complex process of rewriting the original which runs parallel both to the overall view of the language, and to the influences and the balance of power that exists between one culture and another. An intercultural approach to translation means to approach it from the point of view that translation is an act of rewriting an original text. It is also to redefine the aesthetic experience of the original culture into target culture. The translator first lives in the source language aesthetic experience and recreate it for the target language readers. This becomes necessary because at times, certain cultural concepts are completely unknown to the readers in another culture. Explanatory notes must be provided along with the translated text. In a novel or a short story, it may be possible to some extent, but in a poem, where the expression is so compact, and meaning needs to be conveyed instantly for its aesthetic impact to remain intact, bringing the original cultural element might create a mental block. In such situations, giving a cultural parallel as a substitute is the best solution. Fortunately, the universal ways of thinking among the humans, usually have parallels in other cultures. Using a parallel cultural substitute makes it easier for the reader, and also keeps the text loyal to both the cultures and their respective languages. Some examples of these choices are as follows:

The concept of judgment after death has a parallel in Chitragupta in the Hindu culture, which was used in the poem: 'Departed to the Judgment a mighty afternoon'. (ChitraguptaakaDe chaalti zaali ek prachanda dupaar). Leopard has always been a feminine reference, a feminine image in Emily's poems. In Marathi, a leopard could be a bibTyaa (a spotted tiger), or a cheetah, always referred to as a symbol of power and therefore, as masculine. In the poem "Civilization-spurns-the Leopard!" (no. 492), Emily refers to the animal with a pronoun 'her', but in my translations, I have referred to the animal as 'him'. Most culture specific references have been adapted to suit the Marathi language, because any choices to the contrary would not have made the translations look natural in Marathi. I would prefer my translations to look natural 
than otherwise. Attitudes, social customs and traditions, and spiritual matters have been also naturalized. That way, the translations can be received better in a cultural community. For example, references to costume, household objects etc., had to be suitable to appear good and relevant in Marathi.

\section{Managerial Interface with Emily's Poems:}

These decisions discussed earlier were some of the managerial decisions, which helped to diffuse the traffic jams when it came to roadblocks that would not let the translation traffic move ahead. Care was taken in creating new avenues that whatever choices were made did not upset any essential balance of the original poem, and its meaning because I was in love with the poems I was translating, and did not wish to betray them in any way. At each stage, an interpretation of the text mattered significantly in making the choices. The meanings had to be negotiated through an evaluation of both the languages, cultures and the appropriateness of the contexts. The bi-directionalinteraction between the texts had to be managed from the point of view of "confluence" of the texts and the ideas therein rather than their outstanding differences. My translations are "a response to the irrepressible urge to express life" a poet and a sensibility, the "way one paints or bursts into song, splashing colour on the canvas, or modulating melodies for the sheer pleasure of it."

I appreciate the way Malena has worded her experience of translating a work of art, and would like to add a quotation from her regarding the translator's desire for confluence. I share her experience of merging with the text that I found suitable for translation and wished to "achieve confluence and display my (feminist or feminine?) solidarity" with Emily Dickinson's poems by rendering them in as best a Marathi as possible.

The more basic managerial decisions a translator has to make are like the very decision to translate this or that, then the object itself in a certain genre and so on. I interviewed a number of translators of significance that I have known, and asked them why all of them felt like translating something. Except for one who was introduced to translation because he couldn't succeed in creative writing, most others answered that they had an immediate urge to 
share their experience of reading a certain work of art with the people in their own linguistic community. Some thought that they would bring in something nonexistent in their language, thereby contributing to it, and help enhance the richness of their language. Regarding the choice of a genre, some of them were basically fiction readers and enjoyed translating fiction. Others made a decision to translate whatever they came across and liked it, and thought worth translating it. My own decision to translate was two fold: I thought that Emily was an extraordinary poet, with fresh unconventional attitude to death, and other themes, and I had to bring it into my language so that I could share it with others. Apart from that, I was so fascinated by her treatment of various themes, and I had enjoyed reading her poems so much that I wanted to relive that experience and in my own language, while recreating it for others who could not go to the English original. That activity would bring it even closer to my heart. That would allow me to dwell in the experience for prolonged hours. I loved the challenge of translating those poems into Marathi, which gave me an opportunity to test the strength of my language to stand and absorb new modes of meaning.

\section{Conclusion:}

In the process of writing this paper, I reviewed many recent theories of translation, and realized how scholars and researchers are more inclined to state practice- and experience-driven theories of translation. Malena describes the experience quite aptly with regard to what happens in translating from one language to another. "This negotiation of the text,... seeks to retain the dynamics of the structure of the original but ends up in setting off a dynamics of its own, and beyond my control." In addition to subscribing to Malena's views regarding the negotiation of the texts and their meanings, my own theory relies on my awareness of the concepts in modern Linguistics, Sociolinguistics and takes into account the practical constraints the translator has to face. Within these limitations, I strongly believe in bringing out the best possible from the source language into the target language. My experience in translating Emily Dickinson's poetry, and also short stories of Nobel Prize winners, has impressed upon me that a translator 
cannot do without critical faculties and creative faculties of a high order. In the absence of these, translations can be only trash!

\section{References}

Aksoy, Berrin 1941 Translation as Rewriting in Translation Journal, vol. 5, no. 3.

Alvarez, Roman and Carmen-Africa Vidal 1941 Translating: A Political Act, Translation Power Subversion, 1-10, Clevedon: Multilingual Matters Ltd.

Beaugrande, Robert De (In Press) Geopolitics, Geolinguistics and Translatability, In Said Faiq et al. [Eds.] Translation, Identity and Modernity, Amsterdam:Benjamins.

Beaugrande, Robert De 1978 Factors in a Theory of Poetic Translating, Assen: van Gorcum, and Amsterdam: Rodopi.

Beaugrande, Robert De 1996 Theory and Practice of Translation: Prospects for a New Dialectic, Presentation at the United Nations Workshop on Translation.

Boylan, Patrick 2000 Intercultural Empathy and Egocentric / othercentred Translating. University of Rome III, Italy.

Crisafulli, Eduardo 2000 Translation Studies: Eclecticism or Syncretism? Methodological Oppositions in Translation Studies II.

Franklin, Ruth 2000 Black Milk of Language, TNR Online.

Giulia, Guarnieri 2001 The Path to the Nest of Translation, http//www.towerofbabel.com/sections/tome/thepathtothenast oftranslation.

Houbert, Frederic 1998 Translation as a Communication Process, Translation Theory, vol.2, 3.

Joanna, Janecka 1998 The Power of Sound, Translation Journal, vol 5, no. 4.x

Malena, Anne Translation or the Desire for Confluence, Confluence: 1, 1, [iuicode: http//www.icaap.org / iuicode? ..1.1.1] 
Project Description, Poetic Translation and Global English in the 2001-2002 Sawyer Seminar at the University of Chicago: The Range of Contemporary Literacy: The Circulation of Poetry. Sponsored by the Andrew Mellon Foundation.

Pym, Anthony (1992) Translation and Text Transfer, Peter Lang, Frankfurt am Main, Berlin, New York, Paris, Wien. Revised version (1998).

Sarajeva, Sebnem Susam 2000 Theories by the Centre, Data by the Periphery: Towards a "Universal" Translation Studies, Methodological Oppositions in Translation Studies II.

Walker, Michael C. 1998 Translating Poetry: The Works of Arthur Rimbaud From French to English, Translation Journal, vol 2, 4. 